\title{
In-6tream Monitoring on the McKenzie River, Oregon
}

\author{
Laura Marti*, Matt Keeler, Taylor West, Geoffrey Johnson, Kadie Hayward, \\ Kimina Jamison, Robbie Lascheck, Bre Senate, Ashley Sosa, Drew Thompson, \\ Jennifer Vargo[I QYLRQP HQNDOBWXWH
}

\begin{abstract}
Salmon are valued not only as a food source and a symbol of recreation, history, and community, but also as bioindicators of broad ecological functions related to aquatic systems. Countless projects across the Pacific Northwest focus on creating quality habitat and connectivity for salmonids (e.g. salmon, trout) and other aquatic species. Thus, pre- and post-project monitoring of stream restoration techniques such as large woody debris placement and riparian plantings provide crucial information on the success and validity of current techniques. We, the 2013 Stream Stewardship Team from the University of Oregon's Environmental Leadership Program (ELP), conducted pre-project monitoring in the McKenzie River to establish baseline data before restoration efforts. We partnered with the McKenzie Watershed Council at the Berggren Watershed Conservation Area (BWCA), an area of active restoration in the McKenzie Watershed near Eugene, Oregon. At the BWCA, we conducted three in-stream baseline monitoring protocols, including a longitudinal profile, cross sectional profiles, and pebble counts in Channel 2. The longitudinal profile showed that long, deep pools dominated the downstream portion of the channel, while shallow pools and marsh/dry units dominated the upstream portion. Cross sectional profiles documented banks with a large depositional feature of interest that were dominated by reed canary grass. Using our in-stream monitoring results, we hypothesize that the important, but limited, aquatic habitat complexity illustrated by this study will be improved by the addition of large woody debris in the summer of 2014.
\end{abstract}

\section{INTRODUCTION}

The McKenzie River is a critical waterway for sustaining both human and wildlife populations within the larger Willamette River basin. The McKenzie River's headwaters are sourced in the Cascade Mountains, where snowmelt filters through volcanic rock to provide clean drinking water year-round to Eugene city residents (Jefferson et al. 2006). Humans attach recreational values to the McKenzie River as well, which is popular for its boating, rafting, fishing, and picnicking opportunities. Human uses of the McKenzie River Watershed often clash with ecosystem structure and function, negatively impacting wildlife that depends on riverine habitat. Human development of the McKenzie River has resulted in channelization to reduce

*The Stream Stewardship team is part of the Environmental Leadership Program (ELP), an inter-disciplinary learning opportunity in which students gain professional experience while working with community partners to address local environmental needs. The ELP program is housed within the University of Oregon's Environmental Studies Department. To access the Stream Stewardship Team website, visit:

http://sites.google.com/site/elp2013streamstewardship/home. Please direct correspondence to Imarti889@aol.com. 
effects of flooding, removal of large wood to increase recreational safety, and riparian zone destruction or alteration to promote residential or agricultural development (Pess et al. 2012). Additionally, in the 1960s, Cougar Dam and Blue River Dam were built on the McKenzie River specifically for flood control. These dams have altered the flows of sediment and water downstream, greatly reduced the development of mid-channel bars and islands, and promoted a single thread channel lacking areas of spawning gravel accumulation (Ligon et al. 1995). While these changes are beneficial to humans, they also degrade vital habitat for both aquatic and terrestrial species and affect the river's geomorphology (Collins et al. 2012).

When allowed to exist under natural conditions, rivers such as the McKenzie meander over time, creating new channel habitats such as side channels, sloughs, and backwater features (Ligon et al. 1995). Side channels are areas of slower moving water that offer feeding and resting habitat critical for the success of many aquatic species, especially during seasonal high flows when the river's main channel is fast-moving and turbulent. River channelization has prevented the McKenzie River from meandering naturally, and subsequently, the number and quality of side channels has also been diminished (Alsea Geospatial 2000). Anadromous fish leave the sea and travel up rivers to spawn and therefore require a range of different aquatic habitats throughout their life cycle, including slow moving side channel habitat. The degradation of any required habitat types can negatively impact anadromous species' survival. Anadromous salmonids can be used as bioindicators of the changing aquatic environment, meaning that their health as a species can be used to monitor the health of the entire aquatic ecosystem. We will gain information on multiple aspects of the aquatic environment by monitoring habitat characteristics required by the native and endangered Chinook salmon (Oncorhynchus tshawytscha). Required habitat characteristics include the riparian zone large woody debris (LWD) and spawning gravels.

Riparian zones encompass the land area and vegetation directly surrounding the stream channel. Healthy riparian zones can improve water quality, protect rivers from polluted upland surface runoff, and provide valuable habitat conditions such as shading or inputs of organic matter (Collins et al. 2012a; Collins et al. 2012b; Gonzalez \& Garcia 2011; Sunil et al. 2010). In the stream channel, fallen trees with diameters greater than 10 inches are categorized as LWD and create complex river habitats by impacting channel form, water velocity, and the deposition of nutrients and organic matter (Johnson et al. 2005; Nagayama et al. 2009; Pess et al. 2012). By altering water flow, these logs sort gravels suitable for salmon spawning and create scour pools in the channel bed that shelter juvenile fish. Salmon redds are nesting areas composed of spawning gravels that female salmon prepare during spawning season, which is in August and September for McKenzie River spring Chinook salmon (Arthaud et al. 2010). The female salmon requires a specific size class of gravel when preparing a redd that ensures protection and proper aeration of the eggs (Arthaud et al. 2010). Pebble sizes less than $2 \mathrm{~mm}$ limit oxygen flow to the eggs, whereas pebble sizes greater than $10.6 \mathrm{~mm}$ tend to increase the ability of predators to access the eggs (Raleigh 1986). Therefore, the ideal gravel size for Chinook salmon redd construction falls between 2-10.6 mm (Raleigh 1986). Efforts to increase Chinook salmon populations have focused on preserving aquatic habitats that already contain these beneficial characteristics, while also restoring aquatic habitats with the potential to support Chinook salmon throughout their life cycle. 
The McKenzie Watershed Council has partnered with the McKenzie River Trust and initiated multiple projects along the McKenzie River to enhance salmon habitat and create areas of suitable gravel for spawning redds. In 2013, we collected baseline data in side channels of the McKenzie River at the Berggren Watershed Conservation Area (BWCA) (Figure 1). In the main side channel (Channel 2) we conducted cross-sectional profiles, longitudinal profiles, and Bunte-Abt pebble counts to document channel characteristics in advance of planned restoration activities. Following a LWD placement project in the summer of 2014, these baseline data will help the McKenzie Watershed Council track the changes that occur in side channels at the BWCA. In combination, these methods will allow future investigators to compare not only the shape of the channel over time, but also to quantify the power of winter flows. Flood events that are difficult to observe change the channel's form most dramatically. The operating hypothesis of this project, as with a plurality of other river restoration projects in the Pacific Northwest, is that the strategic placement of LWD will create habitat heterogeneity that benefits aquatic communities in side channels of the lower McKenzie River. The measurements and analysis presented here will allow that hypothesis to be evaluated in this restoration priority environment.

\section{STUDY AREA}

The BWCA is a 92-acre property, located in Springfield, Oregon, along the lower McKenzie River (Kezer et al. 2012). The site is comprised of 57 acres of critical riparian habitat that functions as a floodplain forest and 35 acres of residential area and farmland. BWCA was purchased in 2010 by the McKenzie River Trust with funding from Eugene Water and Electric Board and the Bonneville Power Administration, with long-term goals to conserve and protect the McKenzie River ecosystem (Kezer et al. 2012). Many side channel habitats no longer experience overbank flows due to upstream dam construction and associated reduced flows in the McKenzie River. Despite this trend, the BWCA still experiences frequent overbank flows due to high precipitation events in winter and early spring (Kezer et al. 2012). The interconnected system of side channels on the property is unique for the lower McKenzie Watershed, and provides critical rearing and resting habitat for salmonid species. With such a diverse habitat, the BWCA is home to many native species of plants and animals, as well as many invasive plant species that have spread along the property. Native wildlife species found on the property are: the Oregon chub (Oregonichthys crameri), red alder (Alnus rubra), and northern red-legged frog (Rana aurora) (McKenzie River Trust 2013). While native species have evolved to co-exist in this environment, invasive species such as reed canarygrass (Phalaris arundinacea) aggressively suppress the ability of native plant species to perform their function (Cook and Sundberg 2012). 


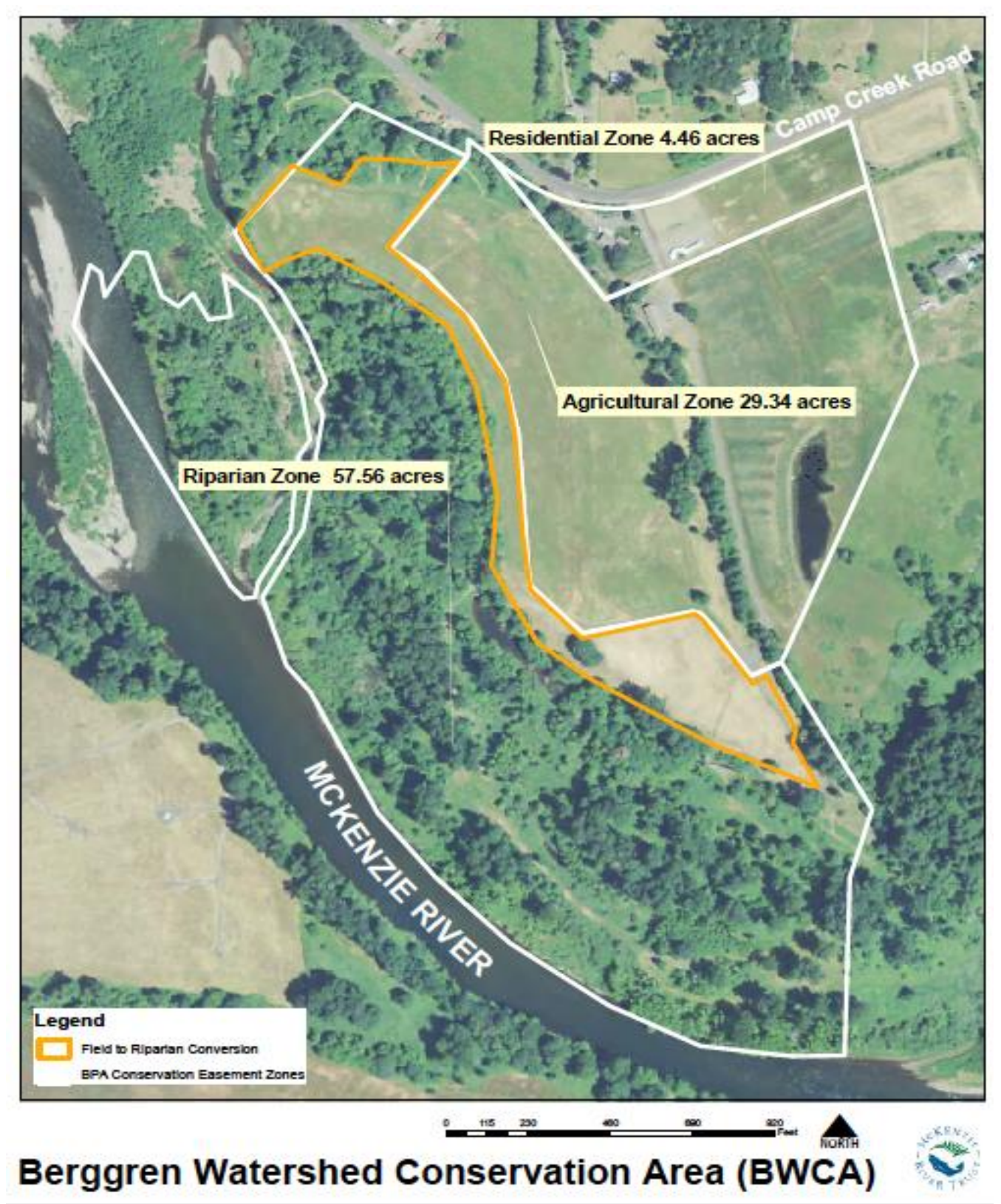

Figure 1: Aerial map of the Berggren Watershed Conservation Area, the entire Riparian zone and most of the Agricultural Zone flood during normal winter and spring flows. Source: McKenzie River Trust.

\section{METHODS}

\subsection{LONGITUDINAL PROFILE}

The longitudinal profile is a critical element of establishing and monitoring a permanent reference site (Harrelson et al. 1994). To conduct a longitudinal profile, technicians measure channel bed and water elevations in the stream's thalweg, the deepest part of the stream. The 
resulting information characterizes overall slope and form and is useful in monitoring channel bed complexity, which is a critical component of functional salmon habitat. All surveying included the use of an auto-level and stadia rod with teams of at least three people. The teams conducted auto-level setup as described by Harrelson et al. (1994), with auto-level operator, recorder, rod holder, and an additional person for maintaining and tracking the channel-length measurement tape, which was laid parallel to the stream.

We established a permanent benchmark for the site, a precise and accurate point in three dimensions, with a non-survey grade elevation of 156.12 meters. We located that datum on the land surface with data from a light detection and ranging, or LiDAR (Oregon Department of Geology and Mineral Industries 2009). LiDAR is a widely employed remote sensing technique that uses light beams and sensors to accurately measure distance from an airplane or helicopter Using the permanent benchmark and georeferenced elevation data, future surveys can use absolute elevation from sea level for assessing how site characteristics change in response to restoration activities. This permanent benchmark can serve as a standard for future longitudinal profiles of Channel 2 (the main side channel), ensuring that data comparison between years is accurate in portraying change. All subsequent stations were related to this first benchmark to maintain a consistent gradient along the channel profile. We collected in-stream foreshot measurements at points in the thalweg and recorded water depth. These measurements were taken every 0.25 - 1 channel widths, depending on how quickly elevation changed in the thalweg, with more frequent measurements taken in sections with an irregular gradient (Bonanno et al. 2011). Turning points were set with backshots to both the previous location and to the benchmark where possible, or to an additional turning point when necessary. In this way, all measurements were related to the benchmark and can be repeated in the same way.

We used scatterplot graphs to plot both bed and water elevation of the surveyed reach. We then calculated a linear regression to give the slope of the surveyed reach of Channel 2 (Figure 3). The mean squared error $\left(\mathrm{R}^{2}\right)$ value of this linear regression is an indicator of bed variability, where a lower $\mathrm{R}^{2}$ value indicates greater bed variability (Mossop and Bradford 2006). We expect that future longitudinal profiles will document increasing channel bed variability, and thus lower $\mathrm{R}^{2}$, following LWD placement, one of primary project goals.

The Longitudinal Profile of Channel 2 (Figure 3) was constructed from two days of data collection on May 17, 2013 ( $\mathrm{m}$ to $350 \mathrm{~m}$ ), and May 24, 2013 (350 $\mathrm{m}$ to $840 \mathrm{~m}$ ). The discharge at the USGS 14162500 McKenzie River near Vida, OR was $4100 \mathrm{cfs}$ and $3900 \mathrm{cfs}$, respectively. Cross sectional profiles were performed at points A, B, C, and D (Figures 5, 6, 7 and 8).

Water surface elevation was estimated from tape distance $450 \mathrm{~m}$ to $550 \mathrm{~m}$ (dashed line) in Figures 3 and 4 due to inconsistent data that may have been caused by faulty instrument setup or data recording discrepancies. This may have affected the bed elevation by $+/-0.2 \mathrm{~m}$ (as calculated from the discrepancy in water surface elevation) in that reach.

\subsection{CROSS SECTIONAL PROFILE}

We conducted four cross sectional surveys at Channel 2 to document changes in riffles and pools over time (Harrelson et al. 1994; Figure 2). Cross sections at riffle locations document 
shallow, fast moving water, whereas deeper, slower moving water is characteristic of cross sections at pool locations. Conducting cross sections at the same locations over multiple years will document any changes in the depth or slope of the banks, which would accompany erosion or deposition by the stream. The cross sections are located within the longitudinal profile (Figures 5, 6, 7 and 8) at river meters 163.85, 332.6, 501, and 704.0. Similar to the longitudinal profile, surveys were conducted using an auto level and metric stadia rod by teams of at least three people, including an instrument operator, a recorder, and a rod holder (Harrelson et al. 1994). All four cross section measurements started at the left bank and ended at bankfull or greater on the right bank (Bonnano et al. 2011). Bankfull was defined as the threshold of the stream channel at which water overflows onto the adjacent floodplain (Harrelson et al. 1994). Water elevation and depth measurements were taken at each significant change in elevation, and at least every three meters where elevation was relatively constant (Bonanno et al. 2011). We then analyzed these data by graphing the cross sectional profile's bed elevations and water depths.

\subsection{BUNTE AND ABT PEBBLE COUNT}

We used a modified version of Bunte and Abt's (2001) pebble count procedure to quantify the streambed substrate of Channel 2 in ecologically important locations. Pebble count 1 was conducted in a glide downstream from a planned woody debris placement, count 2 in a riffle covered by reed canarygrass, and count 3 in a channel section containing the largest naturally-formed deposition bar (Figure 2). Pebble counts were correlated with cross sections in these key locations in order to provide an additional layer of insight into change over time. The distribution of pebble sizes is a proxy for the power of a stream since a more powerful stream can move larger pebbles. Using these data, the McKenzie Watershed Council will be able to assess how sediments are moving in the channel at cross section locations and how powerful the stream is during high flow events. We determined the number of transects at each pebble count location to best characterize the feature of interest. Each pebble count location included a minimum of 100 pebble samples blindly selected every 1 meter along each transect tape. For each pebble count we calculated $\mathrm{D}_{50}$, the median pebble size, and $\mathrm{D}_{84}$, the size of pebble that would move in a flood event. We used a gravelometer to measure the intermediate axis of randomly selected pebbles while also noting whether selected pebbles were embedded within the stream channel. A pebble was considered embedded when it was incorporated in the more permanent structure of the channel, as occurs when a pebble is partially buried by other rocks or sediments. 


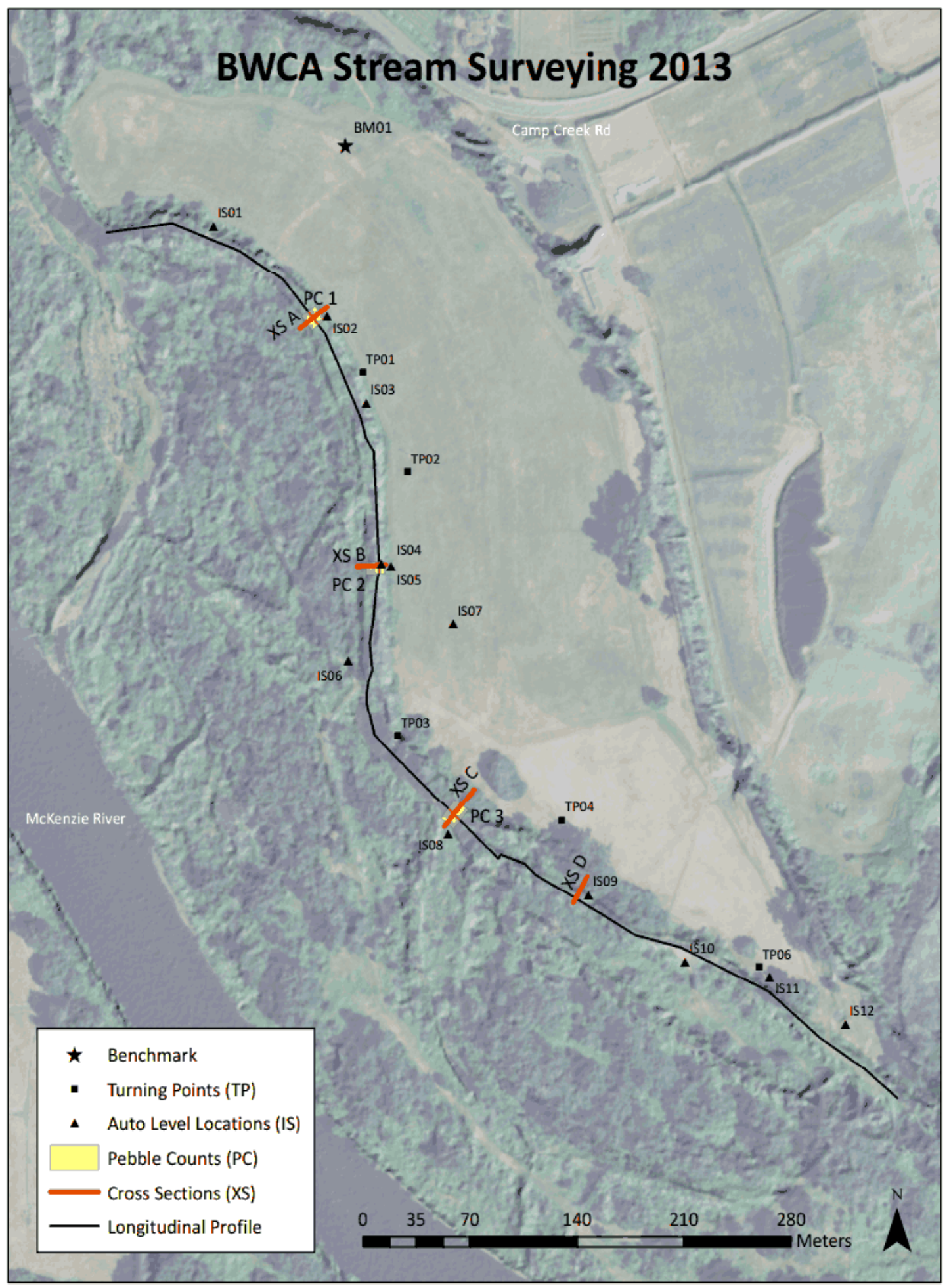

Figure 2: 2013 BWCA in-stream monitoring locations including longitudinal profile, cross sectional profiles, and pebble counts. 


\section{RESULTS}

\subsection{LONGITUDINAL PROFILE}

Long, deep pools made up almost $90 \%$ of Channel 2 from o $\mathrm{m}$ to $550 \mathrm{~m}$. From $550 \mathrm{~m}$ to $840 \mathrm{~m}$, shallow pools and marsh/dry units classified the channel. These dry units are shown on the profile where water surface elevation is non-existent (Figure 3). Additionally, the Longitudinal Profile shows numerous riffles at the May 17 and May 24 discharge levels, which often have scour pools down-stream. A linear regression of the bed elevation data gave a channel slope of $0.28 \%$ (Figure 3). Linear regression was chosen for this reach because it is a relatively short and low gradient compared with larger scale rivers. Additionally, residual pool depth was calculated for pools as shown in blue in Figure 4. The $\mathrm{R}^{2}$ (goodness of fit) value calculated with this linear regression was 0.7658 . This high $\mathrm{R}^{2}$ value demonstrated the low variability in the channel bed elevations.

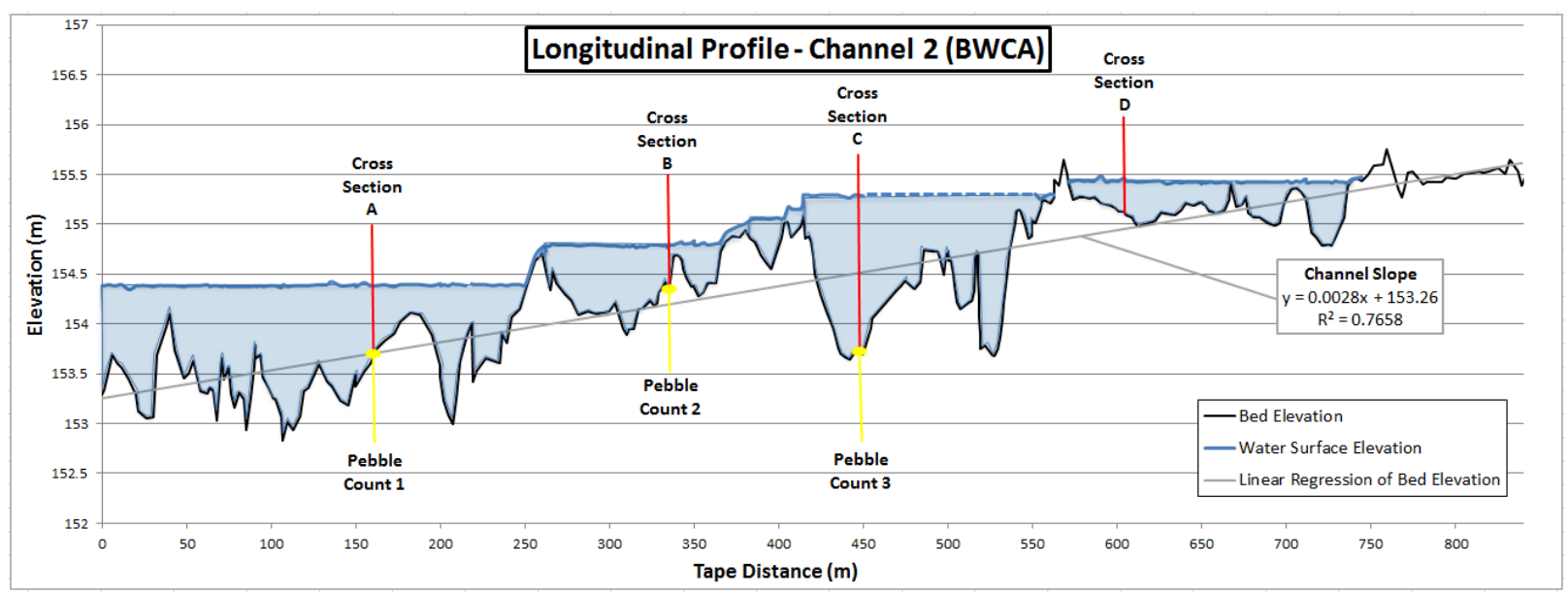

Figure 3: Longitudinal Profile shows the calculation of residual pool depth and channel slope using a linear regression of the bed elevation data. The high $\mathbf{R}^{2}$ value of .7658 indicates low channel bed variability and complexity.

\subsection{CROSS SECTIONAL PROFILE}

Steep bank slopes were seen in cross section A on the right bank, cross section B on the right bank, and in cross section D on the left bank (Figures 4, 5, 6, and 7). Gradually sloping banks were observed in cross sections $\mathrm{B}$ and $\mathrm{C}$ on their left banks. In cross section $\mathrm{C}$ the gravel bar was responsible for this slope. Reed canarygrass was growing into the active channel in many areas, as well as dominating the bank and floodplain. Cross section $\mathrm{C}$ documented the current shape of a large, naturally formed gravel bar, the only feature of its kind in the BWCA. 


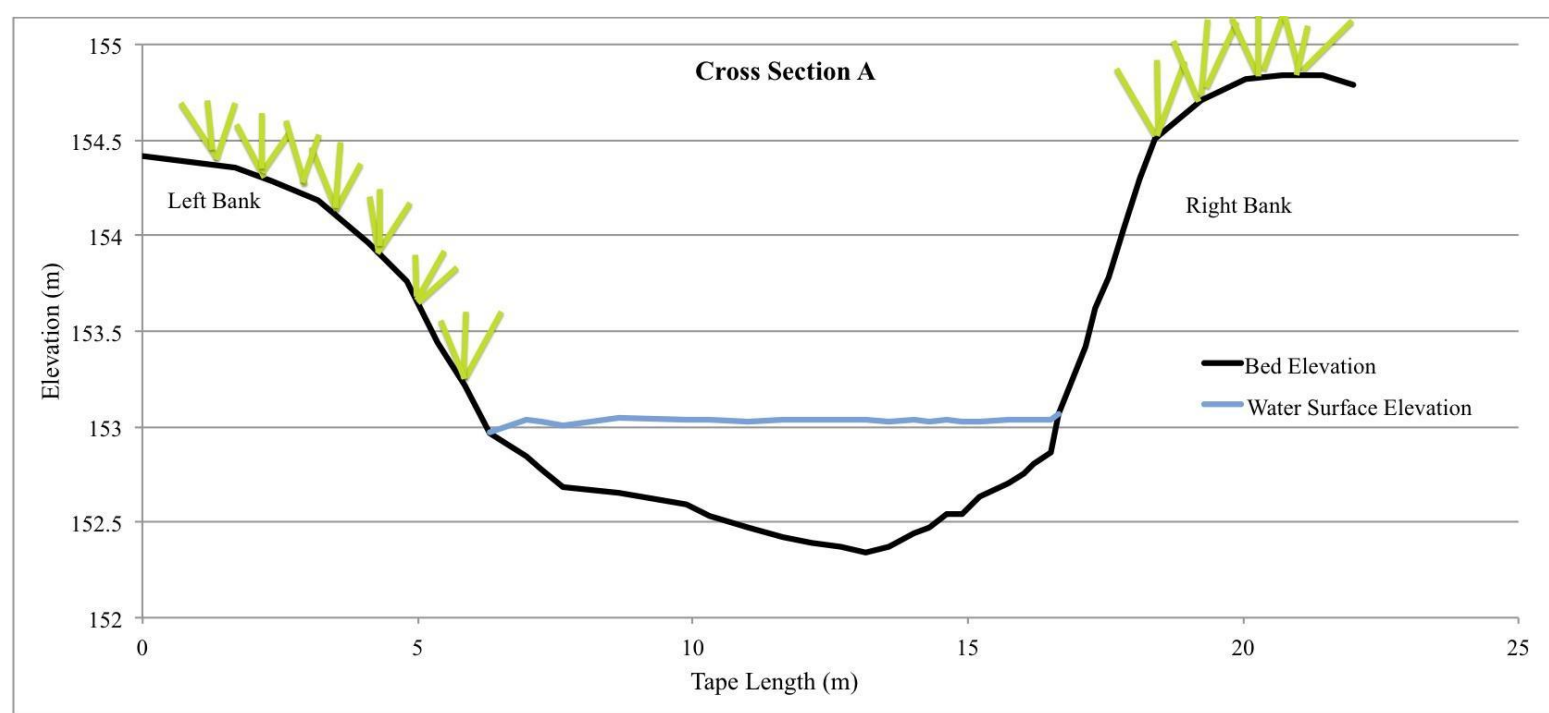

Figure 4: Cross sectional profile $A$ in a pool at river meter 162.85 on the longitudinal profile, showing the steeply cut bank on the right, which indicates local stream channel movement to the right.

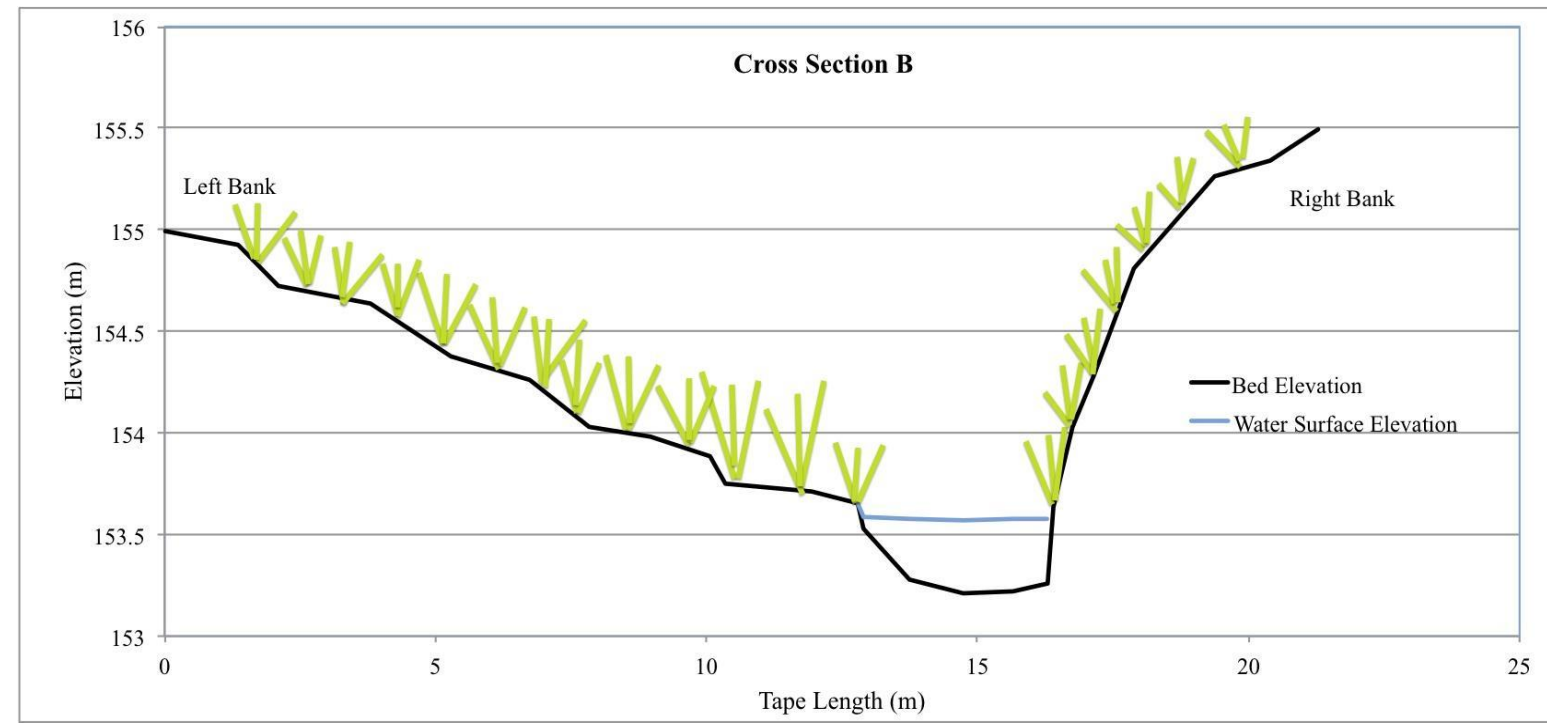

Figure 5: Cross sectional profile $B$ in a riffle (fast, shallow water) at river meter 332.6 on the longitudinal profile, showing encroachment of reed canarygrass restricting the channel. 


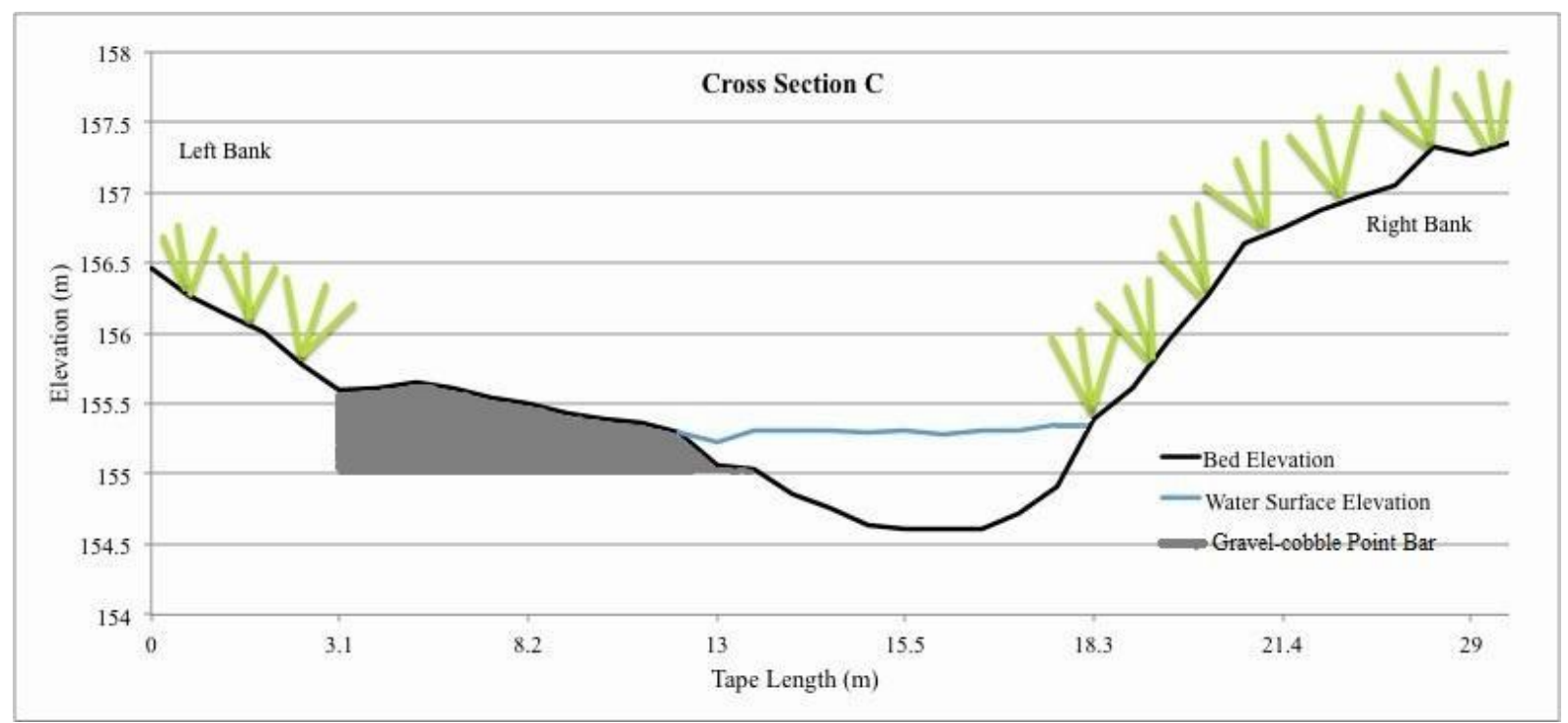

Figure 6: Cross sectional profile $\mathrm{C}$ in a pool at river meter 501 on longitudinal profile. Profile $C$ included a large gravel-cobble point bar in a wide active channel.

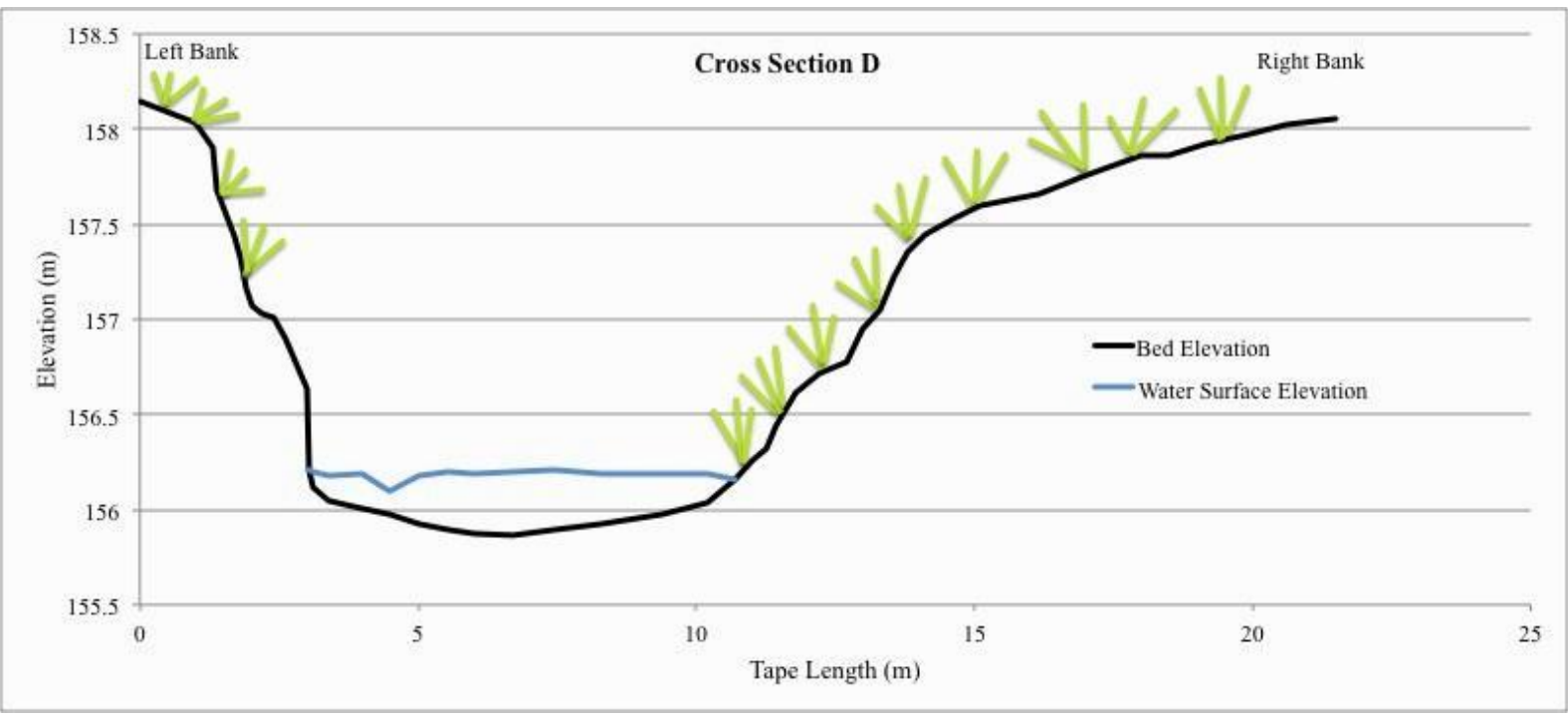

Figure 7: Cross sectional profile $D$ in a pool at river meter 704.0 on the longitudinal profile, steep left bank shows movement of the channel in that direction.

\subsection{BUNTE AND ABT PEBBLE COUNT}

Pebble count data indicated a larger percentage of fine sediment in both counts 2 and 3 as compared to count 1 (Figure 8 ). The full range of particle size classes (from $<2 \mathrm{~mm}-128 \mathrm{~mm}$ ) were represented cumulatively across all three counts, while each individual count recorded a $\mathrm{D}_{50}$ that was gravel sized or smaller. In count $1, \mathrm{D}_{50}$ was $30 \mathrm{~mm}$ and $\mathrm{D}_{84}$ was $63 \mathrm{~mm}$; in count 2 $\mathrm{D}_{50}$ was $16 \mathrm{~mm}$ and $\mathrm{D}_{84}$ was $36 \mathrm{~mm}$; and count $3 \mathrm{D}_{50}$ was $18 \mathrm{~mm}$ and $\mathrm{D}_{84}$ was $30 \mathrm{~mm}$ (Figure 8). 


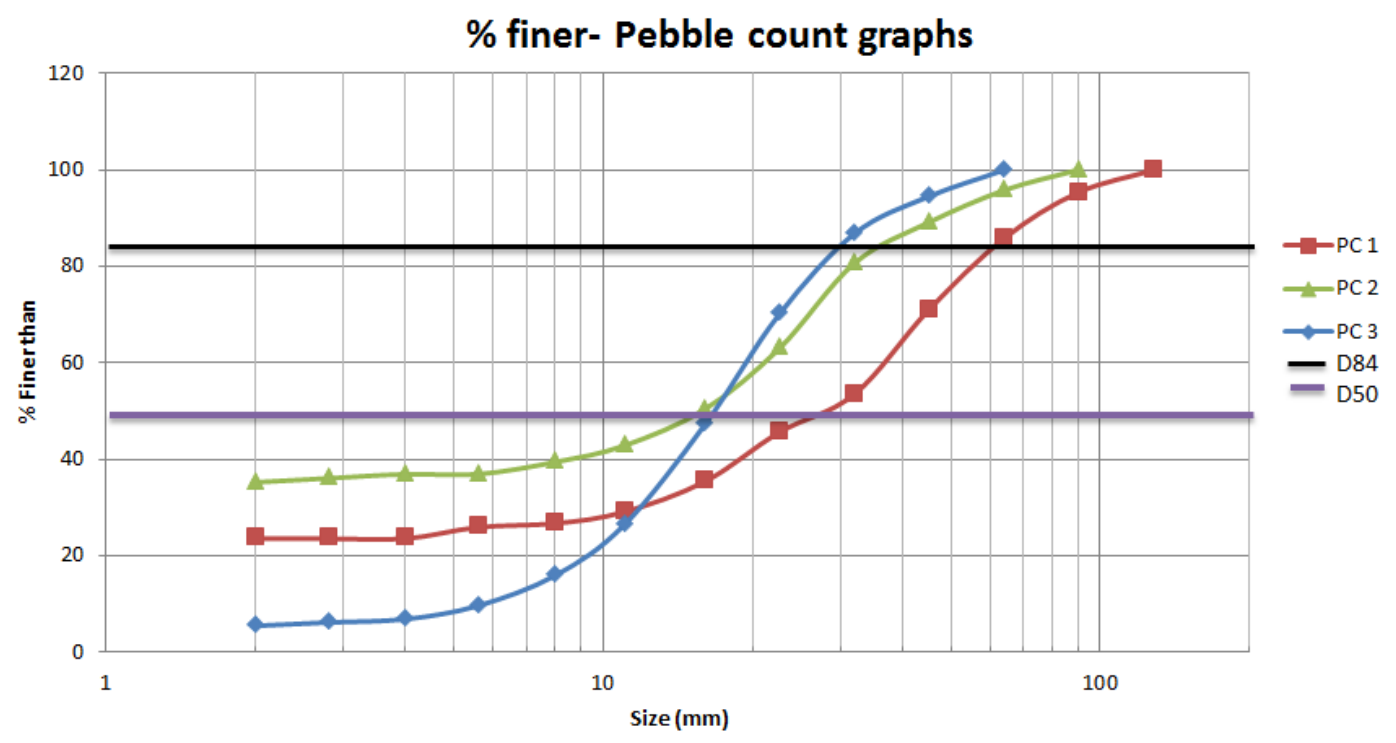

Figure 8: A cumulative distribution of the three pebble counts and percent finer results, with $D_{50}$ and $D_{8_{4}}$ highlighted. $D=$ intermediate axis length of a particle. The ideal particle sizes for Chinook salmon red construction are between 2-10.6 mm (Raleigh 1986).

\section{DISCUSSION}

\subsection{LONGITUDINAL PROFILE}

Our evaluation of the longitudinal profile of Channel 2 at BWCA created a baseline for monitoring the success of a future large woody debris placement. The $\mathrm{R}^{2}$ value calculated from the linear regression (Figure 3) will be compared with future $\mathrm{R}^{2}$ values to reflect channel bed complexity for salmon habitat. Restoration activities will hopefully result in lower $\mathrm{R}^{2}$ values in the future, indicating increased bed form variability and thus habitat complexity. Our longitudinal profile documented the presence of multiple large pools with few riffles or turbulent reaches. It also showed that the pools do not receive overland input from the mainstem McKenzie during summer low flow, as there was no water above the surface above $750 \mathrm{~m}$ of the longitudinal profile. These low flows may result in disconnected channel habitat during the summer. Any through-flow during the time of survey was therefore due to hyporheic flow, where water from the river and the uphill watershed join this channel from underground.

Future surveys can compare the $\mathrm{R}^{2}$ value of a linear regression to this baseline data as well as any changes in location of water inputs. Changes in the error function could be important indicators for changes in fish habitat in these channels. Mossop and Bradford (2006) found a correlation between the error function of a longitudinal profile regression and Chinook salmon population, where population increased as the error function decreased (that is, the habitat became more complex). 


\subsection{CROSS SECTIONAL PROFILE}

Overbank flow events appear to occur at this channel during most years from flood events in the McKenzie. During these events, the channel receives direct input from the river, and these high flows and associated high stream power, are likely responsible for channel formation in BWCA. However, reed canarygrass encroachment may be simplifying these small side channels. By taking root within the active channel margins and altering flow and sediment deposition, reed canarygrass can limit habitat complexity (Martinez 2013).

Cross section A has fairly steep banks, especially its right bank (looking downstream), which may indicate erosion (Figure 4). Erosion of unstable channel banks is an ecological concern because massive influxes of fine sediment inhibit invertebrate species and negatively impact salmon redds by decreasing water and oxygen flows (Raleigh et al. 1986). Cross sections $\mathrm{B}$ and $\mathrm{D}$ also have steep right and left banks respectively, which may indicate channel migration (Figure 5 and 6). The gravel bar (Figure 6) and other depositional features reflected in the cross sections were most likely deposited in high flow and flood events during the winter season. Possible changes due to LWD placement may include the production of scour pools, erosion, deposition, changes in substrate composition, and changes in vegetation.

\subsection{BUNTE AND ABT PEBBLE COUNTS}

Channel 2 has slow moving water and low flows during the spring and summer, but experiences high flows and faster moving water during the fall and winter. The presence of gravels and cobbles indicates the power of a high flow regime as well as deposition from the mainstem McKenzie, which is connected to Channel 2 during high flows. Classifying the pebble sizes at cross sections A, B, and C allows for the McKenzie Watershed Council to track changes over time in locations where changes can be expected in the channel after LWD placement. Count 1 is important because it is downstream from a planned LWD installation; currently this section is characteristic of a glide scoured by seasonal high flows. We expect that the addition of LWD will increase channel heterogeneity both immediately upstream and downstream from the installation and promote the transport of smaller sediments downstream while retaining larger sediments upstream. Count 2 has importance as a riffle being choked with reed canarygrass, an invasive threat to the side channel system with the potential to alter and simplify channel geomorphology in an ecologically destructive way (Martinez 2013). Count 3 was conducted at the location of the largest naturally formed deposition bar within Channel 2; tracking pebble size classes at this location over time will provide insight as to how substrate is moving within the channel in response to high flows.

The calculated $D_{50}$ and $D_{84}$ values are of interest because, in general, the ideal particle sizes for Chinook salmon redd construction are 2 to $10.6 \mathrm{~mm}$ (Raleigh 1986). This particle size range is dependent on fish size because bigger fish can move larger gravels. At BWCA, restoration actions will be designed to increase average particle size to improve suitability for salmon redd construction. Coarser particles allow for better water flow and oxygen levels through the redds, leading to higher survival rates of hatching young (Raleigh 1986). Therefore, 
LWD placement in Channel 2 and other restoration activities will ideally result in an increase of gravel sized particles and decreased levels of fine sediment over time.

\section{RECOMMENDATIONS AND MANAGEMENT IMPLICATIONS}

Based on precedent, we recommend conducting an additional paired cross section and pebble count above the LWD installation site before installation in summer 2014, as it is common to observe changes in channel morphology both above and below LWD installations (Collins et al. 2012a). In addition, we suggest that after the completion of LWD placement in the summer of 2014, subsequent post-treatment monitoring take place the following spring to document initial changes in substrate composition and channel geomorphology. Future data collection should continue to take place during the spring when low flows permit measurement within the thalweg. Furthermore, data collection would ideally take place during similar discharge levels to ensure consistency in data collection and subsequent analysis. Finally, based on our experience with orchestrating complex field operations using accurate instruments where precision is very important, we recommend beginning field days with quality assurance and quality control (QA/QC) tests where all teams compare results from the same location, thus ensuring repeatability. We recommend that whenever possible, the same teams of technicians conduct repeat pebble counts, cross sections and longitudinal reaches in order to reduce bias and the associated error. Since this may be logistically difficult, incorporating QA/QC measures into standard protocols should be routine for ELP teams in the future.

\section{LITERATURE CITED}

Alsea Geospatial, Hardin-Davis, Pacific Wildlife Research, and WaterWork Consulting. 2000. McKenzie river sub-basin assessment. Prepared for McKenzie Watershed Council, Eugene, OR. Available from http://www.mckenziewc.org/assessment.pdf (accessed 1/17/14).

Arthaud, D., C. Greene, K. Guilbault and J. Morrow. 2010. Contrasting life-cycle impacts of stream flow on the Chinook salmon populations. Hydrobiologia 655:171-188. DOI: 10.1007/510750-010-0419-0.

Bonanno, J., N. Gautier, S. Gerlach, L. Holt, T. Howard, O. Hurd and A. Kulha. 2011. Riparian restoration monitoring in the Mckenzie River watershed. University of Oregon Environmental Leadership Program, Eugene, Oregon. Available from https://sites.google.com/site/elprestorationstewardship/home (accessed 1/17/14).

Bunte, K. and S. R. Abt. 2001. Sampling frame for improving pebble count accuracy in coarse gravel-bed streams. Journal of the American Water Resources Association 37: 10011014.

Collins, B.D., D.R. Montgomery, K.L. Fetherston and T.B. Abbe. 2012a. The floodplain largewood cycle hypothesis: a mechanism for the physical and biotic structuring of temperate 
forested alluvial valleys in the Northern Pacific coastal ecoregion. Geomorphology 139: 460-470. DOI: 10.1016/j.geomorph.2011.11.011.

Collins, K.E., C. Doschev, H.G. Rennie and J.G. Ross. 2012b. The effectiveness of riparian 'restoration' on water quality - a case study of lowland streams in Canterbury, New Zealand. Restoration Ecology 21:40-48. DOI: 10.1111/j.1526-100X.2011.00859.x.

Cook, T. and S. Sundberg. 2012. Oregon Flora Project. Available from http:// www.oregonflora.org/checklist.php\# (accessed April 2013).

Gonzalez, M. and D. Garcia. 2011. Riparian quality index (RQI): a methodology for characterizing and assessing the environmental conditions of riparian zones. Limnetica 30:235-254.

Harrelson, C.C., C.L. Rawlins and J.P. Potyondy. 1994. Stream channel reference sites: an illustrated guide to field technique. General Technical Report RM-245. Fort Collins, Colorado: U.S. Department of Agriculture, Forest Service, Rocky Mountain Forest and Range Experiment Station. Available from http://www.fs.fed.us/rm/pubs rm/rm gtr245.pdf (accessed April 2013).

Jefferson, A., G. Grant, and T. Rose. 2006. Influence of volcanic history on groundwater patterns on the west slope of the Oregon High Cascades. Water Resources Research 42: W12411

DOI: 10.1029/2005WRoo4812.

Johnson, S., J. Rodgers, M. Solazzi, and T. Nickelson. 2005. Effects of an increase in large wood on abundance and survival of juvenile salmonids (Oncorhynchus spp.) in an Oregon coastal stream. Canadian Journal of Fisheries and Aquatic Sciences 62:412-424 DOI: 10.1139/Fo4-222.

Kezer, Z., R. Martin, B. Miller, M. Rau, S. Silverstein, O. Slivka, J. Stewart, D. Swanson, V. Truelove, T. Van Hevelingen, T. Woods and K. Young. 2012. Post-project monitoring at the middle McKenzie side channel. University of Oregon Environmental Leadership Program, Eugene, Oregon. Available from https://sites.google.com/site/elp2012streamstewardship/home/products (accessed April 2013).

Ligon, F.K., W.E. Dietrich, and W.J. Trush. 1995. Downstream ecological effects of dams. Bioscience 45 (3): 183-192.

Martinez, A.E. 2013. The geomorphic effects of native and invasive riparian vegetation: Sprague River, Oregon. Dissertation, Department of Geography, University of Oregon.

McKenzie River Trust. 2013. Berggren Watershed Conservation Area. Available from http://mckenzieriver.org/protected-lands/owned-properties/berggren-watershedconservation-area (accessed 1/17/14). 
Mossop, B. and M. Bradford. 2006. Using thalweg profiling to assess and monitor juvenile salmon (Oncorhynchus spp.) habitat in small streams. Canadian Journal of Fisheries and Aquatic Sciences 63:1515-1525. DOI: 10.1139/Fo6-06o.

Nagayama, S., F. Nakamura, Y. Kawaguchi and D. Nakuno. 2009. Summer microhabitat partitioning by different size classes of masu salmon (Oncorhynchus masou) in habitats formed by installed large wood in a large lowland river. Canadian Journal of Fisheries and Aquatic Sciences 66:42-51. DOI: 10.1139/Fo8-191.

Oregon Department of Geology and Mineral Industries. 2009. LiDAR sensing data collection Willamette Valley phase 1. Oregon.

Pess, G.R., M.C. Liermann, M.L. McHenry, R.J. Peters and T.R. Bennett. 2012. Juvenile salmon response to the placement of engineered log jams (ELJS) in the Elwha River, Washington State, USA. River Research and Applications 28:872-881. DOI: $10.1002 / \mathrm{rra} / 1481$.

Sunil, C., R. K. Somashekar, and B. C. Nagaraja. 2010. Riparian vegetation assessment of Cauvery River Basin of South India. Environmental Monitoring and Assessment 170:545-553. 